Journal of Teaching and Learning with Technology, Vol. 5, No. 1, July 2016, pp. 46-58.

doi: 10.14434/jotlt.v5n1.18879

\title{
Students' and Instructor's Attitudes and Receptions of the Viability of Using a Flipped Classroom Instructional Model in a Technology-Enabled Active Learning (TEAL) Classroom: A Preliminary Study
}

\author{
Taotao Long ${ }^{1}$, Joanne Logan ${ }^{2}$, John Cummins ${ }^{3}$, Michael Waugh ${ }^{4}$
}

\begin{abstract}
The flipped classroom is an instructional model in which the students are initially exposed to subject matter concepts outside classroom through instructor-provided video lectures or other pre-class learning materials, and utilize classroom time for active learning, such as problem solving and group work. The Technology-Enabled Active Learning (TEAL) classroom is a small capacity classroom equipped with multimedia projectors, white boards, laptops, and tablets, and utilizes modular tables for flexibly configured working arrangement. This paper reports the initial findings from interviews with five students and the instructor about their experiences, attitudes, and perceptions regarding the Flipped-TEAL instructional approach, which is the use of a flipped classroom instructional strategy in a TEAL classroom. This paper also reports the participants' suggestions for improving the teaching and learning efficiency in the Flipped-TEAL course.
\end{abstract}

Keywords: the flipped classroom, TEAL classroom, interview

\section{Introduction}

The flipped classroom is an instructional model in which students are initially exposed to the learning content outside the classroom through instructor-provided video lectures or other learning materials before class, and utilize in-class time for active learning, such as problem solving, group work, laboratory experiments, and product creation (Gannod, Burge, \& Helmick, 2008; Gerstein, 2011; Warter-Perez \& Dong, 2012). In contrast to the traditional ${ }^{5}$ instructorcentered, lecture-based instructional model, in the flipped classroom, the two main phases of instruction are "flipped," so that the presentation of the initial learning content is completed before class. This first phase of the flipped classroom model is a self-directed learning phase in which students interact with instructor-provided learning materials (O’Neil, Kelly, \& Bone, 2012; Knewton, 2012). The second phase of the flipped classroom instructional model is the active learning experience that occurs during in-class time (Gerstein, 2011). The flipped classroom model can be adapted to many different classroom environments (Warter-Perez \&

\footnotetext{
${ }^{1}$ Department of Educational Psychology and Counseling, The University of Tennessee, 1122 Volunteer Blvd, Knoxville, TN 37996, tlong11@vols.utk.edu

${ }^{2}$ Department of Biosystems Engineering and Soil Science, The University of Tennessee, Knoxville, TN, USA

${ }^{3}$ Department of Plant Sciences, The University of Tennessee, Knoxville, TN, USA

${ }^{4}$ Department of Educational Psychology and Counseling, The University of Tennessee, Knoxville, TN, USA
} 
Dong, 2012), such as a computer lab (Gannod et. al, 2008), a collaborative experimental classroom (Frydenberg, 2012), or the traditional lecture classroom (Gehringer \& Peddycord, 2013).

Creating opportunities to improve students' active learning is one of the aims of the flipped classroom instructional model (Frydenberg, 2012; Warter-Perez \& Dong, 2012). Because of this, the flipped classroom instructional model seems ideally suited for use in a TechnologyEnabled Active Learning (TEAL) classroom. Compared to the traditional lecture classroom, the TEAL classroom provides more helpfulness and opportunities for active learning (Dori, Belcher, Bessette, Danziger, McKinney, \& Hult, 2003; Dori \& Belcher, 2005). TEAL classrooms often have smaller capacities (20-40 students) and more flexible seating arrangements than traditional lecture classrooms. In the TEAL classroom, students usually sit around modular tables in groups (Dori et.al, 2003). Typically, numerous whiteboards, large screens, laptops, and other technologies, are provided for students to use in collaboration and presentation activities (Belcher, 2003; Shieh, 2012). Instructors do not stand at the front of the TEAL classroom but rather move around and interact with students (Belcher, 2003; Breslow, 2010). Student-centered active learning activities, such as collaborative projects and problem solving, are preferred in TEAL classroom instruction.

This paper describes a preliminary study of the use of a flipped classroom model with a TEAL classroom (Flipped-TEAL) at a large research university in the Southeastern US. This preliminary study investigated the instructor's and the students' attitudes and perceptions towards their Flipped-TEAL instructional experiences and their suggestions for improving the teaching and learning effectiveness in the Flipped-TEAL course.

\section{Theoretical Framework}

Davis (1989)'s Technology Acceptance Mode (TAM) was adopted as the theoretical framework of this study. The TAM model is widely used by researchers to predict and explain user acceptance of new information and communication technologies (Davis \& Venkatesh, 1996). The TAM model takes forward the idea that a user's acceptance of new technologies can be predicted from two factors, which are the perceived usefulness and the perceived ease of use (Davis, 1989). Perceived usefulness is defined as the degree to which a user believes that a new technology will enhance job performance, while perceived ease of use is defined as the degree to which a user believes that the new technology would be free of effort (Davis, 1989). Additionally, the TAM model is used as a path model that identifies the impact of external factors such as system design, user characteristics, task characteristics, nature of the development or implementation process, political influences, and organizational structure (Davis, 1989; Davis, 1993; Szajna, 1996). The TAM model is widely used as an instrument to understand how users come to accept a new technology and to continue to use it in education (Roca \& Gagne, 2008; Lee \& Lehto, 2013; Edmunds, Thorpe, \& Conole, 2012).

In this study, the TAM model helps to assess how the users, who are the instructor and the students, perceived the Flipped-TEAL instructional approach on its usefulness and ease of use. The questions from the TAM model about how the Flipped -TEAL instructional approach enhanced the teaching and learning performance, and how the teaching and learning had been eased, were incorporated in the interview of the instructor and the students. 


\section{Method}

Qualitative case study was utilized in this study because it facilitates the exploration of a phenomenon within its context using a variety of data sources (Yin, 2003), and through a variety of perspectives, in order to reveal and understand multiple facets of the phenomenon (Baxter \& Jack, 2008). The data for this study were obtained from semi-structured interviews of the instructor and five students who participated in the Flipped-TEAL course.

\section{The Course}

The course, "Water and Civilization," was an introductory level undergraduate course in environmental soil science at a large research university in Southeastern US. In order to keep the class size small, there were two sections of the course, but the instructor and the syllabus for the two sections were the same. There was one ninety-minute classroom meeting per week in the TEAL classroom.

Before each classroom meeting, the students were required to watch an instructorprovided video which lasted for 20-30 minutes, and then complete an online quiz containing 5-8 questions on the topic in the video. The students were told at the beginning of the semester that each pre-class quiz grade would be calculated in the final course grade. During the in-class time, the students were required to participate in various active learning activities, such as collaborative projects focused on exploration and demonstration, field trips and presentations, and role-play games. Most activities required the students to work collaboratively, but the group numbers and organizations varied across activities. There was no content-related post-class assignment.

\section{The Participants}

The instructor and five students among the 55 students in the two Flipped-TEAL sections volunteered to be interviewed for this study. Although the course is part of the environmental soil science curriculum, the 55 students registered for this course were from various majors in science and engineering. The instructor indicated that for most students, this was their first experience taking a course using the Flipped-TEAL approach.

Five from the ten randomly invited students volunteered to participate in this study. The five students were from different majors (e.g., Environmental Soil Science, Animal Science, Plant Science, Microbiology, Chemical Engineering) and their engagement levels in the learning activities also varied. The instructor was also interviewed in order to collect the data regarding her perspectives on the Flipped-TEAL instruction. The instructor was experienced in using active learning approaches in instruction. She also had the experiences with teaching this course, Water and Civilization, in the TEAL classroom, for more than two years. This study took place during the second time that she used the Flipped-TEAL approach to teach this course.

All the participants participated in the interview voluntarily. The students were also informed that their participation, rejection, or withdrawal from the interview would not affect their grades in this course. 


\section{Data Collection}

An individual, face-to-face, semi-structured interview was conducted with each of the six participants. The interviews varied in length from 30 to 45 minutes. All the interviewees gave informed consent for audio recording of the interviews and were also informed about the purpose of this study. Each recording was transcribed and then destroyed. The student's interview questions were about their experiences in the pre-class and in-class learning activities, their collaboration in class, their attitudes towards learning in the Flipped-TEAL sections, difficulties with respect to their learning performance and motivation, and their suggestions for improving the course. The instructor's interview questions collected information about her preparation for the students' pre-class and in-class learning activities, the learning evaluation activities, difficulties with respect to time and effort investment into instruction, and suggestions for improving the Flipped-TEAL instruction. Table 1 and Table 2 provide examples of pre-designed questions asked during the interviews.

\section{Table 1. Examples of the pre-defined interview questions to students}

What do you think of your learning in this course, in comparison to other courses you have had? Do you think learning in this course is easy?

What difficulties do you have during your learning in this course?

What do you think of this classroom?

What are your suggestions to improve your learning experience in this course?

\section{Table 2. Examples of the pre-defined interview questions to the instructor}

What do you think of your preparation work in this course?

How are about the affordance of this classroom?

How can you improve students' participation in the in-class learning activities?

What do you think of the students' learning performance in this course, in comparison to other courses you have taught?

How do you evaluate students’ learning?

\section{Data Analysis}

Interpretative phenomenological analysis was used for this study. The interviews were audio recorded and transcribed. Then, each transcript was interpreted with the aim of identifying the key features of the interviewee's experience, their cares and concerns (Heaney \& Arroll, 2010; Cornelius, 2013). Next, themes were identified and sorted to identify initial similarities and differences among participants' responses. These themes were then re-analyzed to ensure their applicability across cases. A master table of themes was created to make cross-case comparisons (Cornelius, 2013). Notes and reflections were made during data analysis, and an iterative crosschecking was undertaken by repeated reference back to earlier interpretations and the original transcripts (Cornelius, 2013). Pseudonyms were used to preserve the anonymity of the student participants. The findings of this study were organized by the major themes. 
Long, Logan, Cummins, and Waugh

\section{Findings and Interpretations}

\section{Pre-class Learning: Preparation}

The term "preparation” is used to characterize the participants' insights on students' pre-class learning in the Flipped-TEAL sections. The students shared that the pre-class learning enabled them to prepare for the in-class learning, while the instructor shared thoughts on her preparation for the students' pre-class learning videos and assignments.

All six participants described the pre-class video as a valuable resource for conveying the subject matter knowledge required for the in-class learning activities. Ann stated that by viewing the pre-class videos provided in this course, she came to "know lots of issues outside her world". Martin also expressed that he "liked the videos" because "the videos are interesting and expand my knowledge beyond my major."

Besides the pre-class video, the pre-class assignments were well received by the students. All five students indicated that the pre-class quizzes were useful for them to understand the knowledge covered in the videos, and helped them be prepared for the in-class activities. For example, Ann stated that she had to "pay attention during watching the videos to make sure to pass the quizzes," but "the quizzes are not difficult, not long," so she could "get the credits [for completing the pre-class assignment] in 5 minutes." Bob and Martin both revealed they had to take notes while viewing the videos, in order to get high scores on the pre-class quizzes, and to be prepared for the in-class learning activities.

The instructor focused on different aspects of the values of students' pre-class learning. She indicated that a critical responsibility for instructors who use the flipped classroom model was to "prepare to make the students be prepared for in-class activities."

Referring to the design and development of the pre-class videos, the instructor commented that the technical development was not challenging. She shared that it was convenient to produce the videos through Camtasia, a screen capture software, or in a studio on the university campus, or by using pre-existing Youtube videos. However, the instructor suggested that the content design for the pre-class videos was the key issue. She also shared that "videos should not be too long, but cover all the contents," so she had to "think about what should be covered in the pre-class videos, and what concepts were important to learning, and be really careful to cover all the concepts in videos.” Additionally, the instructor suggested that in designing the pre-class videos and pre-class assignments, instructors should keep in mind the inclass learning activities and relate them to the pre-class learning videos and assignments. The instructor also suggested that the pre-class quiz was necessary to ensure that the students watched the pre-class video and help them to be prepared for class, because "if you [instructor] only ask students to watch the video, they [students] won't.”

\section{In-class Activities: Students Were Engaged}

All six participants agreed that students in the Flipped-TEAL sections were more highly engaged in learning than in the typical lecture-based courses. All five students responded that their learning interest had been improved by participating in these activities and that they enjoyed their experiences in learning by exploration in this course. Bob and Martin compared their experiences in the active learning activities with those in traditional lectures to illustrate that their learning in the Flipped-TEAL sections was more engaging and required more in-depth thinking. 
They indicated that the students had to think and explore by themselves, such as "seeking the materials and choosing which one is most suitable to present" (Bob), and be responsible for their own learning for "contributing to [their] personal learning process" (Martin).

The students also explained that their exploration in problem solving, collaborative projects, field trips, and other active learning activities in class, enabled them to have a "different way of learning” (David). The students explained that through getting engaged in activities, they "studied together, explained to each other, and presented" (Linda), became "more knowledgeable about the subject based on the raw information [known from pre-class videos] to explore and study in an attempt to enhance the learning experience" (Ann), could "think deeper" (Linda), and could "think more" (Martin). The students also indicated that in the collaborative projects, they had to "think of some different answers, debate [with group mates]" (David), explaining and presenting their personal understandings to others who were "in other fields" and "understood in different ways” (David). In this way, the students' skills in independent thinking, exploration, and presentation, were improved. The students' positive reception to the in-class activities was also reflected by the instructor's statement "the attendance in this class was 95\%," which was not typical.

\section{Students’ Collaboration: Get Improved from Conflicts}

The collaborative project was the most frequently used active learning activity design in this course. All the participants agreed that collaboration and communication could make students' learning experiences more relevant and interesting. Students' collaboration also offered them the opportunities to view others' insights critically, such as "seeing more through others' comment” (Ann), "learning better from others [I am] not familiar with" (Linda). The collaboration led to more in-depth thinking, because the students "not only shared personal ideas, but also forced back [reflected on] to the ideas of others" (Bob).

Moreover, students learned to respect others' viewpoints and deal with the conflicts that occurred in their group work. Three students stated that although conflicts usually happened in collaboration, all group members understood that conflicts were unavoidable in collaboration and could make their group work better. These three students used the expressions "view clash" (David), "different ideas" (Ann), and "debate” (Martin) to describe the conflicts that happened in their groups, instead of the word "conflict." They all stated that the "conflicts" stemmed from group members' various backgrounds, but if all the group members "verified [others' viewpoints]” (Ann), “debated [among group members], went back [to reflect], read again and decided which one was found to be better [for completing the group work]" (Martin), then (who) "mixed together" (David) opinions of group members, their different ideas could be meaningfully incorporated into the group work. In this sense, conflicts, and their resolution processes helped students learn, and improved the quality of their collaborative work.

\section{Students' Collaboration: Instructor's Facilitation}

In this course, the instructor never told the students how to collaborate with each other. Rather, she only assigned them to different groups and informed them of the topic and requirement. The instructor suggested that in flipped classroom instruction, instructors should not intervene in students' collaboration, because students need to learn how to collaborate by themselves, but 
instructors should work to facilitate students' collaboration, in order to improve every students' participation, active thinking, and creation.

From the instructor's viewpoint, peer pressure facilitated students' collaboration and participation in their group work. If someone in a group did not participate, s/he would feel guilty, because group mates were monitoring and urging them to participate. It also freed up some of the instructor's effort in classroom management. In order to keep the peer pressure and promote students' sense of collective engagement, the instructor highlighted that all the students in the same group would share the same grade based on the quality of their group work.

Additionally, the instructor suggested that in the students' collaborative projects, rotating roles enabled students to "play different roles" in order to "learn different things" (Linda). In this course, the instructor only assigned and rotated the role of group leader. The role rotation approach offered students opportunities to fulfill different responsibilities within the group collaborative projects, and to improve their abilities not only in learning subject matter, but also in organizing and communicating their ideas.

The instructor emphasized the importance of rotating the role of group leader. She "rotated roles to make everyone be the leader at least once." In her opinion, working as a group leader required a relatively higher level of engagement than just doing the work the leader assigned. From the students' viewpoints, group leaders always "kept everyone in the group on their roles” (Martin), assigned each group member the work, and "organized all the group work" (Martin). Students also shared that group leaders "had a hard job to understand all the information and present in class" (David). However, some of the students felt that their group mates behaved more passively in the collaborative projects. They "contributed no ideas, just did whatever told to do" (Ann). The role rotation approach forced these students into a higher level of engagement and independent thinking.

\section{Evaluation: Keep Balanced and Fair}

In this study, all participants responded that the formative evaluation approach used in this course decreased students' anxiety about exams and improved their motivation to learn. According to the students, they had to complete "lots of pieces of assignments to get the final grade” (Linda), but these assignments “were not tiring or boring” (Linda). Formative evaluation kept students engaged in each learning assignment, both pre-class and in-class, in order to get a high final grade in this course. However, the students indicated that it did not take too much time to complete the assignments, because "they were not difficult" (Linda), and the students would do well if they were "just focused" (David).

The instructor also suggested that the formative evaluation approach could keep the learning evaluation fair in the flipped classroom course, because it was impossible for a student to fail or get a low course grade by only doing poorly on one or two exams. Additionally, the instructor suggested that the learning evaluation was kept fair by keeping the balance between the group work and individual work. This evaluation approach not only helped to improve students' collaborative learning, but also individual learning.

\section{The TEAL Classroom: More Opportunities}

According to the participants' responses, the TEAL classroom, which offers a flexible seating arrangement and technology-rich environment, was very helpful in facilitating the teaching and 
learning during the in-class active learning activities. The participants responded that compared with the other learning environments, the TEAL classroom seemed to foster students' collaboration. The seating arrangement could create a relaxed atmosphere for students' collaboration. The technical tools in the TEAL classroom were also helpful for students' information search, collaborative exploration, and presentation.

The participants indicated that the flexible seating arrangement enabled them to conveniently have many kinds of activities in this course. They stated that the modular tables and movable chairs allowed them to easily shift among groups of different numbers of members in collaborative activities. Additionally, all the five student participants shared that they had a deep impression on a role-play game about how water resources were distributed in the states along Colorado River. All of them indicated that the flexible seating arrangement enabled them to have this game in an easy way. In this game, the students put several modular tables together to "make a long table to simulate a river for the role play game about water resources distribution” (Ann). In the TEAL classroom, it was convenient to put modular tables together in a long row to simulate the river. Then the students were divided into different groups. Each group was assigned the role of a state along Colorado River and sat along the "long table." In this role-play game, the number of tokens a group had was used to represent the quantity of water resources a state possessed. The students explored and transferred the tokens to simulate the water resources transition among the states in different situations. After the game, it was also convenient to disassemble the "long table" and to make other seating arrangements. The instructor also shared that it was very difficult, even impossible, to have this role-play game in other kinds of classrooms, especially the traditional lecture classroom, because it would be difficult to configure the furniture.

The students also shared that in the technology-rich environment in the TEAL classroom, they could "choose whatever would like [to use in learning]" (Bob). In the TEAL classroom, it was very convenient for students to search information, explore, present, and demonstrate. In the collaborative projects, each student could work on a laptop. The students could also use their own mobile devices. Each group could have its own large screen and white board for collaborative exploration, presentation, and sharing. The students could shift their laptops' connections to the large screen very smoothly, so the collaboration inside groups, the communication between different groups, and the presentation to the whole class was very convenient. Besides the large screen, the students could use the white board for discussion and presentation, and the instructor could take a picture of the completed group work on the white board for evaluation. Additionally, tablets were also available in the TEAL classroom. Students could use tablets for information search and sharing. The instructor could also use tablets to assess students' understanding and get real-time feedback with Nearpod, which is an application that enables instructors to use their tablets to manage content on students' mobile devices.

When asking the perceived advantages of the TEAL classroom, the instructor shared that there were more "opportunities" in the TEAL classroom for students. She explained that "more opportunities" meant more resources for students' learning, more technologies to support their exploration and presentation, and more active learning experiences. The instructor also felt that she had more "opportunities" to implement the flipped classroom active learning activities by using the TEAL classroom, and to facilitate students' collaborative activities easily. According to her, the seating arrangement in the TEAL classroom enabled her to quickly assign students into groups in collaborative active learning activities. She also indicated that she "enjoyed" facilitating students' active learning in the TEAL classroom, because the seating arrangement 
allowed her to reach any group within only a few steps, and to interact with students during their exploration.

\section{Suggestions}

The participants' suggestions on how to improve the teaching and learning effectiveness in the Flipped-TEAL sections are summarized in the paragraphs below.

First, the pre-class videos should not be too long. Linda and Bob complained that several videos were a little too long, which required too much time in pre-class learning. The instructor also noticed and suggested that the pre-class videos in the flipped classroom instruction should not be longer than 20 minutes, or the students' attention might be lost.

Second, the instructor and students suggested that the topic design for the in-class activities was critical. The students responded that the topics in this course motivated them to integrate the knowledge learned from this course, and the knowledge from their own subject fields, in completing the activities. The instructor also suggested the topics should be about realworld situations, and "without absolutely right answers."

Third, although the technology-rich environment in the TEAL classroom was appreciated by the participants, the distractions offered by technology could be problematic. Ann argued that sometimes when she and her group mates used some technologies for the first time, such as a Wiki for collaboration, too much time was spent on solving the technical problems associated with the technical tools, and their engagement with the subject matter was reduced.

Fourth, Linda complained that sometimes in collaboration, the group members rarely viewed group mates' work, and just sent their individual work to the group leader for integration. The instructor also indicated that some students did not pay enough attention to other groups' presentations. The participants suggested that a peer critique requirement might improve the type of students' engagement.

\section{Discussion}

Overall, according to the students and instructor, the implementation of the Flipped-TEAL approach in this study was successful in improving students' learning motivation and skills in collaboration, problem solving, and presentation. The Flipped-TEAL approach was wellreceived by the instructor and the students. However, this study identified some challenges associated with the Flipped-TEAL instructional approach. First, the technology-rich environment may become a distraction for students from the subject matter learning. Second, the class size of the TEAL classroom is usually small, and it might be a limitation for implementing the FlippedTEAL approach in other large courses.

In this study, the flipped classroom model was combined with a TEAL classroom environment. Instructor-provided videos and various technologies in the TEAL classroom played an important role in improving students' active learning in this course. However, it is important for educators to keep in mind that the flipped classroom is fundamentally a strategy that empowers students to consume information outside of class and demonstrate understanding of subject matter concepts in various ways during class (Makice, 2011). Various media technologies and student-centered active learning activities, can be adapted in flipped classroom instruction to enhance its teaching and learning effectiveness (O’Neil et al., 2012). 
Technology, and the technology-rich environment in the TEAL classroom, facilitated teaching and learning in the flipped classroom model, but cannot be viewed as a necessary component or a main focus of the flipped classroom model. The primary focus of the flipped classroom model should be on increasing students' engagement (Miller, 2012). A key aspect of the flipped classroom is to create opportunities for students' active learning (Gerstein, 2011; Frydenberg, 2012). This study confirmed that the success of the design and implementation of the flipped classroom model depends on whether the design of learning environment, choice of resources and technologies, and organization of learning activities can actually meet the students’ needs. Moreover, the flipped classroom can be adapted in a variety of learning environments. The TEAL classroom is only one kind of learning environment for the flipped classroom instructional approach, and this study confirmed that the TEAL classroom is a good place for the implementation of student-centered active in-class learning activities, but, the technologies present in the TEAL classroom might serve as a possible distraction for students' learning. This study also confirmed that the TEAL classroom could be helpful for students' collaboration, but the peer review and critique on completed assignments among students was not enough, and it might be improved by revising the requirements of in-class activities.

\section{Limitations}

A limitation of this study was that although the participants included students and an instructor, all the participants were from one course, so their viewpoints might be similar to some extent. Additionally, only six participants were involved in this study. As a result, this study may have limited generalizability.

Another limitation was that the data was collected only through interview. The results may yield to the shortcoming on internal validity (Merriam, 2009). Triangulation using multiple sources of data should be used in future research (Merriam, 2009). Additionally, the results of this study were all based on participants' self-reported data. No actual assessment of students' learning outcomes was made.

This study was a preliminary study with limited participants. Future research should involve more participants from various subject fields and various targeted groups of students. Future research should also focus on a closed examination on how the Flipped-TEAL approach affects students' learning in a rigorous experimental design, in order to examine the potential benefits of adopting the Flipped-TEAL approach in instruction.

\section{Conclusion}

As a preliminary study on the instructional approach of using the flipped classroom instructional strategy in a TEAL classroom, this qualitative case study examined the instructor's and the students' attitudes and perceptions towards their teaching and learning experiences in the Flipped-TEAL sections, together with their suggestions for improving the teaching and learning effectiveness in this course. This study demonstrated that the Flipped-TEAL instructional approach was well-received and successfully implemented in engaging students in active learning, and improving students' skills in problem solving and collaboration. This study suggested that the pre-class learning phase was important in preparing students for the in-class student-centered active learning experiences. In this sense, when preparing for the FlippedTEAL sections, instructors should focus on how to help students be prepared for the in-class 
learning, and the pre-class learning videos should not be too long. According to this study, students were actively engaged in the in-class, student-centered, active learning activities, and their collaboration skills were improved from solving the conflicts by themselves. However, the instructor's facilitation could not be ignored, in order to keep each student actively engaged in the collaborative work. A peer critique requirement might also be introduced to improve students' review of other groups' work. This study also suggested that the formative evaluation approach used in this Flipped-TEAL course decreased students' anxiety about exams and improved their learning motivation, but instructors should be careful to keep the formative evaluation balanced and fair. Additionally, this study suggested that instructors should be careful that the technology-rich environment in the TEAL classroom might become a distraction for students and should focus on the topic design of the in-class learning activities. However, the TEAL classroom could provide more opportunities for in-class active learning when instructors use the flipped classroom instructional model.

\section{References}

Baxter, P. \& Jack, S. (2008). Qualitative Case Study Methodology: Study Design and Implementation for Novice Researchers. The Qualitative Report, 13(4), 544-559.

Belcher, J. W. (2003). Improving Student Understanding with TEAL. The MIT Faculty Newsletter, 16(2), 1-10.

Breslow, L. (2010). Wrestling with Pedagogical Change: The TEAL Initiative at MIT. Change The Magazine of Higher Learning, 42(5), 23-29.

Cornelius, S. (2013). Facilitating in a demanding environment: experiences of teaching in virtual classrooms using web conferencing. British Journal of Educational Technology, 45(2), 260-271.

Davis, F. D. (1989). Perceived usefulness, perceived ease of use, and user acceptance of information technology. MIS Quarterly, 13(3): 319-340.

Davis, F. D. (1993). User Acceptance of Information Technology: System Characteristics, User Perceptions and Behavioral Impacts. International Journal of Man-Machine Studies, 38(3), 475487.

Davis, F. D., \& Venkatesh, V. (1996). A critical assessment of potential measurement biases in the technology acceptance model: three experiments. International Journal of Human-Computer Studies, 45(1), 19-45.

Dori, Y. J., \& Belcher, J. (2005). How Does Technology-Enabled Active Learning Affect Undergraduate Students' Understanding of Electromagnetism Concepts. The Journal of the Learning Sciences, 14(2), 243-279.

Dori, Y. J., Belcher, J., Bessette, M., Danziger, M., McKinney, A., \& Hult, E. (2003).

Technology for active learning. Materials Today, 6(12), 44-49. 
Edmunds, R., Thorpe, M., \& Conole, G. (2012). Student attitudes towards and use of ICT in course study, work and social activity: A technology acceptance model approach. British Journal of Educational Technology, 43, 71-84.

Frydenberg, M. (2013). Flipping Excel. Information Systems Education Journal, 11(1), 63-73.

Gannod, G., Burge, J., \& Helmick, M. (2008). Using the Inverted Classroom to teach Software Engineering Using the Inverted Classroom to Teach Software Engineering. Paper presented at The 30th International Conference on Software Engineering 2008. Leipsig, Germany.

Gehringer, E. F. \& Peddycord, W. P. (2013). The Inverted-Lecture Model: A Case Study in Computer Architecture. Paper presented at Conference for Association for Computing Machinery's Special Interest Group on Computer Science Education 2013. Denver, CO.

Gerstein, J. (2011). The Flipped Classroom Model: A Full Picture. Retrieved from http://usergeneratededucation.wordpress.com/2011/06/13/the-flipped-classroom-model-a-fullpicture/

Heaney, R. \& Arroll, M. (2010, September). Staff perceptions of second life. Paper presented at $20^{\text {th }}$ Conference of the Association for Learning Technology, Nottingham.

Knewton (2012, March 8). The flipped classroom infographic: A new method of teaching is turning the traditional classroom on its head. Retrieved from http://www.knewton.com/flippedclassroom/

Lee, D. Y. \& Lehto, M. R. (2013). User acceptance of YouTube for procedural learning: An extension of the Technology Acceptance Model. Computer \& Education, 61, 193-208.

Makice, K. (2011, December 10). Flipping the Classroom Requires More Than Video. Retrieved from http:/www.wired.com/geekdad/2012/04/flipping-the-classroom/

Merriam, S. (2009). Qualitative research: A guide to design and implementation. San Francisco, CA: Jossey-Bass.

Miller, A. (2012, March 7). Five best practices for the flipped classroom. Retrieved from http://www.edutopia.org/blog/flipped-classroom-best-practices-andrew-miller

O'Neil, K., Kelly, T. \& Bone, S. (2012). We Turned Learning On Its Ear: Flipping the Developmental Classroom. In T. Amiel \& B. Wilson (Eds.), Proceedings of World Conference on Educational Media and Technology 2012 (pp. 2752-2756). Association for the Advancement of Computing in Education (AACE).

Roca, J. C. \& Gagne, M. (2008). Understanding e-learning continuance intention in the workplace: a self-determination theory perspective. Computers in Human Behavior, 24, 15851604. 
Long, Logan, Cummins, and Waugh

Szajna, B. (1996). Empirical Evaluation of the Revised Technology Acceptance Model. Management Science, 42(1), 85-92.

Shieh, R. S. (2012). The Impact of Technology-Enabled Active Learning (TEAL) Implementation on Student Learning and Teachers' Teaching in a High School Context. Computer \& Education, 59(2), 206-214.

Warter-Perez. N., \& Dong. J. (2012, April). Flipping the Classroom: How to Embed Inquiry and Design Project into a Digital Engineering Lecture. Paper presented at American Society for Engineering Education-Pacific South West Section Conference, San Luis Obispo, CA.

Yin, R. K. (2003). Case study research: Design and methods (3rd ed.). Thousand Oaks, CA: Sage. 